\title{
Characteristics of Patients with Thalassemia Major in AL- Muthana Governorate and description of their Blood groups influences, consanguineous marriage problem.
}

\author{
${ }^{1}$ Mohamed Maroof Middib (Ph.D) ${ }^{2}$ Fadil Abass Al- Moktar( MD Pediatrion ) \\ ${ }^{3}$ Abdul Kareem S. Saqban ( Ph.D) \\ ${ }^{(1,3)}$ College of Veterinary Medicine / Green University of Al Qasim /Iraq ${ }^{(2)}$ College of Medicine/ University of \\ Al Muthanna
}

\begin{abstract}
Thirty patients, twenty two were males, eight were females and two ware normal control, aging between one year and twenty two year. Twenty nine (99\%) patients, were consanguineous their parents are relative one was normal merge and studied in the Feminine and Children Hospital of Al Samawa/Iraq. All patients had spleenomegaly and Hepatomegaly with teeth deformities. Thirteen males with cardiomegaly and SIX females with bronchopneumonia. All patients with low hemoglobin (less than $9.13 \mathrm{~g} / \mathrm{dl}$ compared to the average control which was $10.72-14.76 \mathrm{~g} / \mathrm{dl}$

Thirteen boys and six females Thalassemia patients had cardiomegaly with blood groups of $O+, A+$ and $B+$ Eight patients had Bronchopneumonia seven males and one female with blood groups of $O+$ and $B+$ blood groups, compared to control group no (blood groups were checked). Blood groups were investigated to find ten patients with blood group $O+$, two were $O-$, seven $A+$, eight with $B+$ and one $B-$.Bon deformalities was found in teeth and jaws bones in patients with thalassemia.
\end{abstract}

Key words: hemoglobin, genetic disease, cardiac size, blood groups

\section{Introduction:}

Thalassemia is divided in to Alpha and beta Thalassemia . Regular blood transfusion therapy leads to iron overload-related complications including endocrine complication such as growth retardation, failure of sexual maturation, diabetes mellitus, and insufficiency of the parathyroid, thyroid, pituitary, and less commonly adrenal glands, dilated cardiomyopathy, liver fibrosis and cirrhosis, Patients with thalassemia major accumulate body iron over time as a consequence of continuous red blood cell transfusions which cause hepatic, endocrine, and cardiac complications, (1). The biochemical signature of $\beta$-thalassemia is a reduced synthesis of the $\beta$ globin subunit of $\mathrm{HbA}(\alpha 2 \beta 2)$. Individuals inheriting two $\beta$-thalassemic alleles suffering a deficit in $\beta$-chain production, and leads to excess production of $\alpha$-globin , (2). It is genetically inherited hemoglobin disorder, expressing severe chronic hemolytic anemia .

Life-long red blood cell (RBC) transfusion remains the main treatment for severe thalassemia. The development of anti-RBC antibodies (alloantibodies and/or autoantibodies) can significantly complicate transfusion therapy. Some alloantibodies are hemolytic and may cause, though not invariably, hemolytic transfusion reactions and limit the availability of further safe transfusion. Others are clinically insignificant. Erythrocyte autoantibodies appear less frequently, but they can result in clinical hemolysis and in difficulty in cross-matching blood. Patients with autoantibodies may have a higher transfusion rate and often require immunosuppressive drugs, a splenectomy, or alternative treatments., (3) and (4). Despite the recognition of autoantibodies as transfusion-associated risks, little is known about the extent and causes of these phenomena among thalassemia patients or the appropriate prevention methods. Approaches for prevention or treatment of alloimmunization are under debate. They range from provision of RBCs matched for all the major antigens associated with clinically significant antibodies to blood matched only for antibodies that have already been made. Reasons for controversy as to the best approach lay in the fact that many alloantibodies are not harmful, and expensive prevention methods may therefore benefit only some patients, (5), (6). 1994, and , 7 ).

Alloimmunization to erythrocyte antigens is one of the major complications of regular blood transfusions, particularly in patients who are chronically transfused. The factors for alloimmunization are complex and involve three main contributing elements: the RBC antigenic difference between the donor and the recipient, the recipient's immune status, and the immunomodulatory effect of the allogenic blood transfusions on the recipient's immune system. The development of anti-RBC antibodies (alloantibodies or autoantibodies) can significantly complicate transfusion therapy. Some alloantibodies are hemolytic and may cause various hemolytic transfusion reactions and limit the availability of further safe transfusion. Erythrocyte autoantibodies appear less frequently, but they can result in clinical hemolysis and in difficulty in crossmatching blood. Patients with autoantibodies may have a higher transfusion rate and often require 
immunosuppressive drugs, a splenectomy, or alternative treatments. Alloimmunization is often a less significant problem in patients whose transfusion is initiated before the age of $3 . \underline{4}$ A centralized system of RBC alloantibody records is available, which provides a valuable opportunity to evaluate the frequency of alloimmunization and autoimmunization to RBC antigens in multi-transfused thalassemia major patients. This was attributed to a form of immune tolerance, and in general alloimmunization increased with the number of blood transfusions, Experience also showed it is more likely when transfusion is intermittent and begun beyond early childhood.

The most common alloantibodies identified in most of the reports were those of the Rhesus (Rh) and Kell systems (8)., (9). and (10). Some studies identified alloantibodies of the Kidd and Duffy systems in addition to the Rh and Kell systems (11). , (12). and (13). Sensitization to red cell antigens; however, is not confined only to thalassemia and sickle cell anemia patients, it occurs in the general transfused population with a frequency of Abdelaal1999, 1-3\%, and in those multitransfused due to different clinical disorders, the frequencies were found to be $11.8 \%, 6 \%, 2.9 \%$ and $9 \% \quad$ (14)., (15). , (16). , (17). ,(18). and (19). Transfusion dependent thalassemia patients may also develop red blood cell autoantibodies, in addition to red blood cell alloantibodie, (20). , and (21). Although autoantibodies develop less frequently than alloantibodies, they may cause clinical hemolysis, difficulty in cross-matching blood and finding compatable .

\section{Materials and Methods:}

The aim of this study was to understand the disease profile like hemoglobin and blood groups relationship distribution in expressing the disease in relation to abnormalities diagnosed by $\mathrm{x}$ ray and respiratory system. Thalassemia major patients, where studied in Maternity and childrenHospital in AlMuthanna city during 2010. Twenty nine out of 30 patients were belonged to closely relative parents, consegues mirages. Diagnosing Thalassemia by Hemoglobin-Electrophoresis which is one of the methods used to study Thalassemia. The system were used was (BioRad-D-10-France), ModelDB7D12006.

Three milliliters of fresh blood placed in test tube, then the rest materials are followed as indicated in the directions came with the system. Hepatomegaly and splenomegaly were detected by palpation (Clinical examination). Chest $x$ Ray model used is a Shimadzu, Japan/Model 06/1.2P164/DK-85, to investigate cardiomegaly and bronchopneumonia. Also blood grouping and Rh system used in this study was anti-A monoclonal and Anti-B monoclonal and Anti-D monoclonal IgG+IgM (Spanish Spinreact reagent).

Patients had face deformities teeth malocclusion due to Bone Marrow expansion of the face due to erythroid hyperplasia;Allthalassemic patients had a Class II skeletal base relationship. The average ANB angle was significantly larger than the controls in dental stages 2 and $3(P<0.05)$. Mandibular base length (Ar-Gn) was significantly less in thalassaemic patients than in controls, with the greatest differences $(P<0.001)$ found in the younger age group.

Complete Blood Cell Count (CBC) was done using blood count computer system. This system is called Sysmex model KX-21, Japan (Sysmex) corporation). The operator computer system was used for doing the Complete Blood Cell count (CBC), such as Red Blood Cell, White Blood Cell. This system employs three detectors, one for WBC, the RBC and the third is for hemoglobin detection. Also this system give an out put for the abnormal samples. One cubic centimeter of blood placed in $5 \mathrm{ml}$ plastic tube with Heparin as anticoagulant agent to avoid clotting. Then the tube was inserted in the system tube holder uncovered, making the content of the tube sucked up by the system. Out put of the results will be ready on the screen. Then the system then supplying data slip used as a record. This out put slip contains, WBC, RBC, HB, MCV, MCH MCHC, Platelets, lymphocytes and Neutrophils.

\section{Results:}

Thirty patients were studied in Al Muthanna Maternity and children hospital. Twenty nine patients were belonging to cousin parents (consignees mirage). Two patients were expressing very low hemoglobin level ranging between $6.1-6.7 \mathrm{~g} / \mathrm{dl}$, see table one . one patients showed extremely low hemoglobin level, less then twelve yare, and 3.7 in less then seventeen year $6 \mathrm{~g} / \mathrm{dl}$,(Table-1). penitents were ranged in ten year periods . Blood groups were investigated to find seven were infected with cardiomegaly patients with blood group $\mathrm{O}+$, and Broncchopnia three patients also were O-, expression cardiomegaly and one O- expression Broncchopnia, also the study showd that patients in $\mathrm{A}+$ expression cardiomegaly five patients, also $\mathrm{B}+$, six cardiomegaly patients, but only one Broncchopnia patients ,also only one B+ have normal person , and one B+ expression one cardiomegaly and tow were an checked person, see (Table-2). 
Table-1.Hemoglobin level according to the age:

\begin{tabular}{|c|c|c|c|c|}
\hline P\# & Sex & בAGE & $\mathrm{HB}, \mathrm{g} / \mathrm{dl}$ & Control,g/dl \\
\hline 1 & $\bar{F}$ & $\overline{~ 1 \mathrm{y}}$ & 7.78 & 9-13.1 \\
\hline 2 & $\overline{\mathrm{M}}$ & $2.5 \mathrm{ys}$ & 8.3 & $10.7-13.1$ \\
\hline 3 & $\mathrm{M}$ & 4ys & 8 & 11.1-14.7 \\
\hline 4 & $\mathrm{M}$ & 4ys & 9.8 & 11.14 .7 \\
\hline 5 & $\bar{M}$ & 5ys & 7.7 & 11.1-14.7 \\
\hline 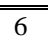 & $\bar{F}$ & 6ys & $\bar{~} 6$ & 111.1-14.7 \\
\hline 7 & $\bar{F}$ & 7.4 & 7.4 & 111.1-14.7 \\
\hline 8 & $\mathrm{M}$ & $8 \mathrm{ys}$ & 5.6 & 11.1-14.7 \\
\hline 9 & F & 8 8yrs & 9.8 & $111.1-14.7$ \\
\hline 10 & $\overline{\mathrm{M}}$ & 8yrs & $\overline{77.8}$ & 11.1-14.7 \\
\hline 11 & $\bar{M}$ & 10ys & 6.7 & 111.1-14.7 \\
\hline 12 & $\overline{\mathrm{M}}$ & 10ys & 7.9 & 111.1-14.7 \\
\hline 13 & $\mathrm{M}$ & 111ys & 10.1 & 111.1-14.7 \\
\hline 14 & $\overline{\mathrm{M}}$ & 11ys & 6.1 & 1.1-14.7 \\
\hline 15 & $\mathrm{M}$ & 11ys & 7 & 11.1-14.7 \\
\hline 16 & $\bar{F}$ & $211 \mathrm{ys}$ & 10.4 & $111.1-14.7$ \\
\hline 17 & $\mathrm{M}$ & $12 \mathrm{ys}$ & $\overline{9.1}$ & 12.8-16.8 \\
\hline 18 & $\mathrm{M}$ & $12 \mathrm{ys}$ & 7 & 12.8-16.8 \\
\hline 19 & $\bar{M}$ & $12 \mathrm{ys}$ & 8 & $12-16$ \\
\hline 20 & $\mathrm{M}$ & $12 \mathrm{ys}$ & $\overline{5}$ & $12-16$ \\
\hline 21 & $\bar{M}$ & 13ys & 8.3 & $\overline{12-16}$ \\
\hline 22 & $\mathrm{M}$ & 15ys & 7 & $12-16$ \\
\hline 23 & $\overline{\mathrm{M}}$ & 16ys & 8 & $12-16$ \\
\hline 24 & $\overline{\mathrm{M}}$ & $17 \mathrm{ys}$ & 8 & $12-16$ \\
\hline 25 & $\bar{F}$ & $17 \mathrm{ys}$ & 8 & $\overline{12-16}$ \\
\hline 26 & $\overline{\mathrm{M}}$ & $17 \mathrm{ys}$ & 3.7 & 12-16 \\
\hline 27 & $\overline{\mathrm{M}}$ & 18ys & 8.7 & $12-16$ \\
\hline 28 & $\mathrm{M}$ & $21 \mathrm{ys}$ & 10.4 & 12-16 \\
\hline 29 & $\bar{F}$ & $22 \mathrm{ys}$ & 7.4 & $12-16$ \\
\hline 30 & $\bar{F}$ & $22 y s$ & 10 & $12-16$ \\
\hline
\end{tabular}

Table-2: Blood group, and Chest X Ray finding in twenty seven Thalassemia patients related to sex and age.

\begin{tabular}{|c|c|c|c|c|}
\hline \# & Age & Sex & Blood group & CXR \\
\hline 1 & $17 y$ & $\mathrm{M}$ & $\mathrm{O}+$ & Cardiomegaly \\
\hline 2 & $12 \mathrm{YS}$ & $\mathrm{M}$ & $\mathrm{A}+$ & $=$ \\
\hline 3 & 7.4YS & $\bar{F}$ & $\overline{\mathrm{A}+}$ & $=$ \\
\hline 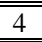 & $8 \mathrm{YS}$ & $\bar{F}$ & $\mathrm{O+}$ & $=$ \\
\hline 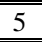 & $22 \mathrm{YS}$ & $\bar{F}$ & $\mathrm{~B}+$ & $=$ \\
\hline 6 & $5 \mathrm{YS}$ & $\mathrm{M}$ & $\mathrm{A}+$ & $=$ \\
\hline 7 & $10 \mathrm{YS}$ & $\mathrm{M}$ & $0+$ & $=$ \\
\hline 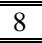 & $13 \mathrm{YS}$ & $\mathrm{M}$ & $0+$ & =+bronchopneumonia \\
\hline 9 & $8 \mathrm{YS}$ & M & $\mathrm{B}+$ & $==$ \\
\hline 10 & $2.5 \mathrm{YS}$ & $\mathrm{M}$ & $0+$ & Normal \\
\hline 111 & $10 \mathrm{YS}$ & $\mathrm{M}$ & $\mathrm{B}+$ & Cardio+Bronchop \\
\hline 12 & $11 \mathrm{YS}$ & $\mathrm{M}$ & $\mathrm{B}+$ & Cardiomegaly \\
\hline 13 & 4YS & $\mathrm{M}$ & $0+$ & =+Bronchop \\
\hline 14 & $1.4 \mathrm{YS}$ & F & $\mathrm{B}+$ & Normal \\
\hline 15 & $21 \mathrm{YS}$ & M & $\mathrm{B}+$ & Cardiomegaly \\
\hline 16 & $11 \mathrm{YS}$ & $\mathrm{F}$ & $\mathrm{A}+$ & $=$ \\
\hline 17 & $17 \mathrm{YS}$ & $\overline{\mathrm{F}}$ & $\mathrm{A}+$ & =+Bronchop \\
\hline 18 & $12 \mathrm{YS}$ & $\mathrm{M}$ & $\mathrm{O}+$ & Cardiomegaly \\
\hline 19 & $8 \mathrm{YS}$ & $\mathrm{M}$ & B- & $=$ \\
\hline 20 & $22 \mathrm{YS}$ & $\overline{\mathrm{F}}$ & $\mathrm{O+}$ & $=$ \\
\hline
\end{tabular}




\begin{tabular}{|c|c|c|c|c|}
\hline 21 & $17 \mathrm{YS}$ & $\mathrm{M}$ & $\mathrm{O}+$ & $=+$ Bronchop \\
\hline 22 & $11 \mathrm{YS}$ & $\mathrm{M}$ & $\mathrm{B}+$ & Cardiomegaly \\
\hline 23 & $4 \mathrm{ys}$ & $\mathrm{M}$ & $\mathrm{A}+$ & Cardiomegaly \\
\hline 24 & $16 Y S$ & $\mathrm{M}$ & $\mathrm{O}-$ & $=$ \\
\hline 25 & $12 \mathrm{YS}$ & $\mathrm{M}$ & $\mathrm{O}-$ & $=+$ Bronchop \\
\hline 26 & $11 \mathrm{YS}$ & $\mathrm{M}$ & $\mathrm{A}+$ & $==$ \\
\hline 27 & $12 \mathrm{YS}$ & $\mathrm{F}$ & $\mathrm{B}+$ & Cardiomegaly \\
\hline 28 & $18 \mathrm{YS}$ & $\mathrm{M}$ & $\mathrm{O}+$ & $=$ \\
\hline
\end{tabular}

\section{Discussion:}

Couples related marriage as a second cousins, account for an estimated $10.4 \%$ of the global population. The highest rates of consanguineous marriage occur in north and sub-Saharan Africa, the Middle East, and west, central, and south Asia, (22) . Because marriage within clan, tribe, caste, has been a longestablished tradition in the third world to give a problem in this type of marriage. In the following disorders such as thalassemia, AIDS, heart disease, , smoking addiction, premarital carrier is a form of genetic counseling .

The genetic counseling is offered to consanguineous counseling procedures for better life during marriage. Bedouin community characterized by high prevalence of genetic diseases and a religious ban on abortion in other parts of the world considered as a harmful practice. Even though this method is not used in Iraq but, so many genetic diseases are common. The above are explained why the custom is still extremely prevalent, particularly in Arab countries, Here in Al Muthanna population due to the people vesting the hospital came from different parts of the governorate, I found that high percentage of relative marriages as seen in my study (99\%),from all Al muthana population..

Twenty nine cases out of 30 patients resembling $99 \%$ were a generation of relative marriages is established in those thalassemic patients. With the diseases prevalence is close to $100 \%$ are suffering from Hepato-spleenomegaly.Also few patients had high blood pressure, jaundice and anemia and the chest X ray showed that most of them had cardiomegaly (data not showed). In order to identify specific genes by counseling marriage we will enable more conditions to limit relative marriage.

Hemoglobin level was found abnormally low in all patients. 25 patients were low, 2 patients were very low and three patients were very and very low level comparing to the control level showed in table- 1 . All patients in the study were received frequent blood transfusion throughout their suffering time from thalassemia.Table-2 shoaled that, twenty six patients of thirty were expressing low level of hemoglobin, ranging $7 \mathrm{~g} / \mathrm{dl}$ or more .Two patients were expressing very low hemoglobin level ranging between $6.1-6.7 \mathrm{~g} / \mathrm{dl}$. Four patients showed very very low hemoglobin level which is less than $\mathrm{g} / \mathrm{dl}$. The study showed ten patients with blood group $\mathrm{O}+$, two was $\mathrm{O}-$, seven with $\mathrm{A}+$, eight with $\mathrm{B}+$ and one $\mathrm{B}-$.The chest $\mathrm{X}$ Ray showed two patient were normal but eighteen patients had cardiomegaly and eight patients with cardiomegaly and bronchopneumonia.

The result showed that blood group was segregated on $\mathrm{O}+$ with 10 patients and then $\mathrm{B}+$ were 8 patients but A+ were 7 patients. The exception was two patient in O- and one in B-.Since blood groups are genetically determenent, those result showed that since Thalassemia is genetic all parameters studed were controlled by patients genetics also.

Thalassaemia is one of a group of genetic blood disorders referred to as haemoglobinopathies. These disorders, which mainly include thalassaemia and sickle cell anaemia, are among the most common hereditary diseases worldwide: around 7\% of the global population carry an abnormal haemoglobin gene, and more than half a million affected children are born each year.Thalassaemia International .

Patients with Beta- thalassaemia major - the most severe type of thalassaemia - cannot make normal red blood cells and do not produce enough haemoglobin. This leads to severe anaemia with consequences such as retarded growth, bone deformities, reduced energy - and ultimately death at a young age if $\beta$-thalassemia (thal) are inherited defects in the rate of synthesis of $\beta$ globin chains of hemoglobin, that are widely distributed throughout the world, with considerable frequencies in the Eastern Mediterranean countries, including Iraq . The two most northern provinces of Iraq are Dohuk and Erbil which cover together an area of around 20000 square kilometers, bordering Iran and Turkey, with a population of around 2.2 million of mostly ethnic Kurds. Thalassemia major is an important problem in these two provinces as well as other parts of the country. 


\section{References}

[1]. Galanello R, Agus A, Campus S, Danjou F, Giardina PJ, Grady RW.2010. Combined iron chelation therapy. Ann N Y Acad Sci.

[2]. Cao A, [1]- Galanello, 2010. Beta-thalassemia .

[3]. Argiolu F, Diana G, Arnone M. High dose intravenous immunoglobulin in the management of autoimmune hemolytic anemia complicating thalassemia major.

[4]. Cianciulli P, Radiotherapy combined with erythropoietin for the treatment of extramedullary hematopoiesis in an alloimmunized patient with thalassemia intermedia. Ann Hematol. 1996;73:379-381.

[5]. Ness PM. To match or not to match: the question for chronically transfused patients with sickle cell anemia. Transfusion. 1994;34:558-561.

[6]. Ness PM, Shirey RS, Thoman SK, Buck SA. The differentiation of delayed serologic and delayed hemolytic transfusion reaction: incidence, long term serologic findings, and clinical significance. Transfusion. 1990;34:688-693.

[7]. Fluit CRMG, Kunst VAJM, Drenthe-Schonk AM. Incidence of red cell antibodies after multiple blood transfusion. Transfusion 1990;30:532-5.

[8]. Michail-Merianou V, Pamphili-Panousopoulou L, Piperi-Lowes L,et al. Alloimmunization to red cell antigens in Thalassemia: Comparative study of usual versus Better-Match Transfusion. Vox Sang 1987;52:95-8.

[9]. Spanos et al.1990 m 1-4. Experience also showed it is more likely when transfusion is intermittent and begun beyond early childhood.

[10]. Ameen etal.20033-5. Some studies identified alloantibodies of the Kidd and Duffy systems in addition to the Rh and Kell systems .

[11]. Coles et al.1981, Sirchia et al.1985 and Hmida et al. 19941 Sensitization to red cell antigens; however, is not confined only to thalassemia and sickle cell anemia patients,

[12]. Sirchia G, Zanella A, Parravicini A, et al. Red cell alloantibodies

[13]. Hmida S, Mojaat N, Maamar M, et al. Red cell alloantibodies in patients with haemoglobinopathies. Nouv Rev Fr Hematol 1994;36:363-6.

[14]. Ramsey G. Red Cell Antibodies and the new Immunology. Lab Med 1994;25:

[15]. Heddle NM, Soutar RL, O'Hoski PL, et al. A prospective study to determine the frequency and clinical significance of alloimmunization post-transfusion. Br J Haematol 1995;91:1000-5..

[16]. Fluit CRMG, Kunst VAJM, Drenthe-Schonk AM. Incidence of red cell antibodies after multiple blood transfusion. Transfusion. 1990; 30:532-535.

[17]. Chow MP, Hu HY, Lyou JY, et al. Red cells, HLA and platelet antibody formation in patients with multiple transfusions. Acta Haematol 1994;92:57-60.

[18]. Hoeltge GA, Domen RE, Rybicki LA, et al. Mutiple Red cell transfusions and alloimmunization. Experience with 6996 Antibodies detected in a total of 159262 patients from 1993. Arch Pathol Lab Med 1995;119:42-5.

[19]. Schonewilli H, Haak HL, Van Zijl AM. Alloimmunization after blood transfusion in patients with hematologic and oncologic diseases. Transfusion 1999;37:763-71.

[20]. Ameen R, Al-Shemmari S, Al-Humood S,et al. RBC alloimmunization and autoimmunization among transfusion-dependent Arab thalassemia patients. Transfusion 2003;43:1604-10.

[21]. Acta Haematol 1990;83:65-8.

[22]. Singer ST, Wu V, Mignacca R. Alloimmunization and erythrocyte autoimmunization in transfusion dependent thalassemia patients of predominantly Asian descent. Blood 2000;96:3369-73.

[23]. BittlesA. H. and M. L. Black, 2010. Consanguinity, human evolution, and complex diseases.PNAS.107 (1):1779-1786. 